\title{
Евтропкова Д.С. \\ Воздействие здорового образа жизни на здоровье пожилых людей
}

Петрозаводский государственный университет (Россия, Петрозаводск)

doi: 10.18411/trnio-11-2021-153

\section{Аннотация}

В данной статье рассказывается о влиянии здорового образа жизни на здоровье человека в пожилом возрасте. Воздействие здорового образа жизни, как на работу организма в целом, так и на определенные его функции. Целью нашего исследования, результаты которого представлены в данной статье, является воздействие здорового образа жизни на здоровье пожилых людей и отношение данной категории людей к здоровому образу жизни.

Ключевые слова: здоровый образ жизни, пожилой возраст, здоровье.

\section{Abstract}

This article describes the impact of a healthy lifestyle on the health of people in old age. The impact of a healthy lifestyle, both on the work of the body as a whole, and on its certain functions. The purpose of our research, the results of which are presented in this article, is the impact of a healthy lifestyle on the health of elderly people and the attitude of this category of people to a healthy lifestyle.

Keywords: a healthy lifestyle, old age, health.

Здоровый образ жизни человека содержит в себе комплекс оздоровительных мероприятий, направленный на укрепление физического и психического здоровья человека, а также повышения моральной и физической работоспособности. Актуальностью выбранной темы заключается в необходимости в формировании здорового образа жизни у людей, которые, к сожалению, не имеют достаточно знаний в этом вопросе, но очень хотят поддержать свое здоровье.

Целью нашего исследования воздействия здорового образа жизни на здоровье пожилых людей. Для проведения исследования был использован метод анкетирования по выбранной теме. В нем собран ряд вопросов, которые помогут наилучшим образом отразить отношение пожилых людей к здоровому образу жизни путем анализирования данных. Характеристика выборки составила 20 человек пожилого возраста, среди которых было 10 мужчин и 10 женщин. Возраст респондентов - от 60 до 82 лет. Благодаря графикам или диаграммам по каждому вопросу анкеты можно наглядно увидеть соотношение мнений разных людей.

Раздел «рацион питания».

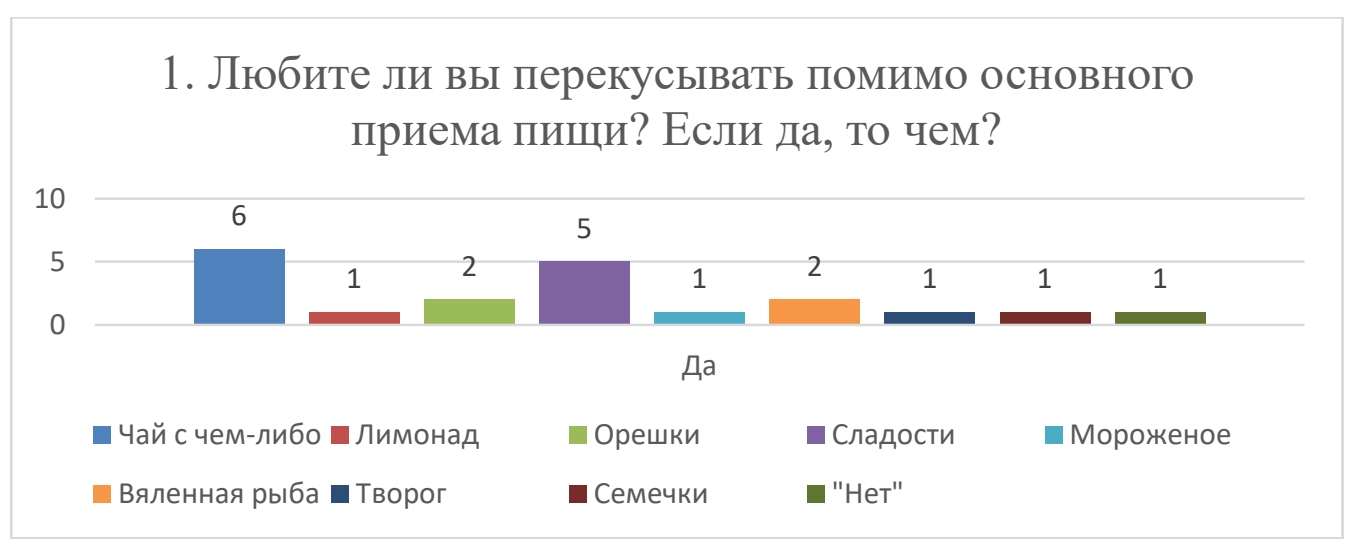

Большинство людей преклонного возраста любят перекусить чем-либо, помимо основного приема пищи, что может привести к неправильному пищеварению. 
2. Часто ли вы едите рыбу? (морепродукты)

20 ответов

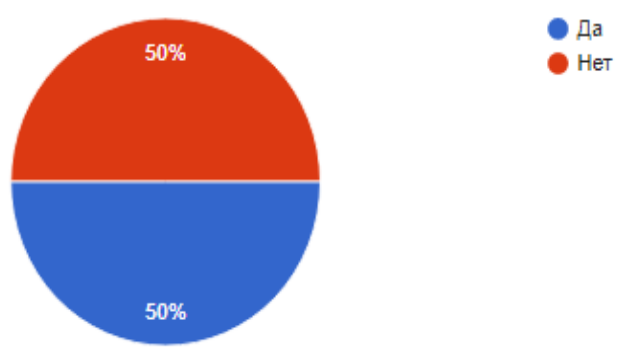

По результатам можно увидеть, что люди преклонного возраста употребляют рыбу, но не всегда так часто, как требуется в их возрасте.

3. Часто ли вы едите кисломолочные продукты?
20 ответов

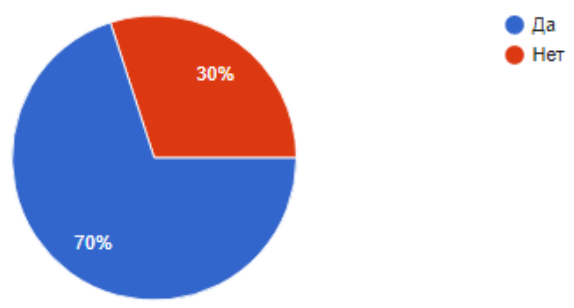

Большинство людей преклонного возраста употребляют кисломолочные продукты.
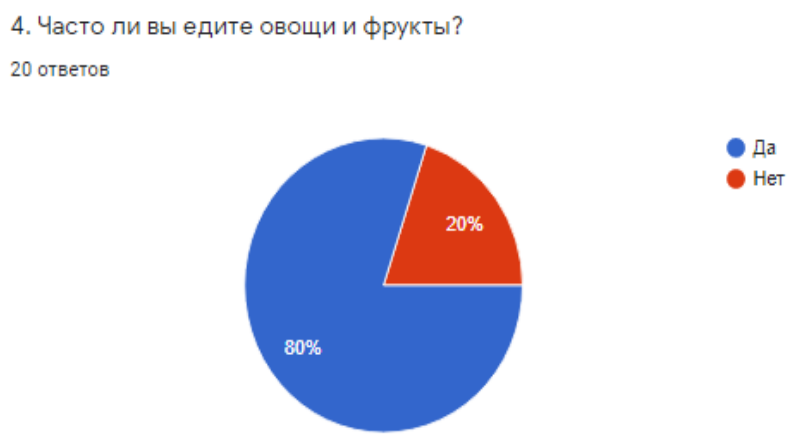

Большинство людей преклонного возраста употребляют овощи и фрукты.

5. Считаете ли вы разнообразным ваш рацион?

20 ответов

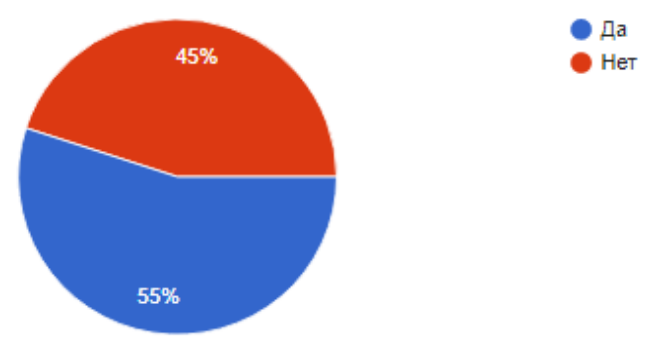

Больше половины людей преклонного возраста считают свой рацион питания разнообразным. 
6. Каким чаще способом вы обрабатываете пищу для употребления?

20 ответов

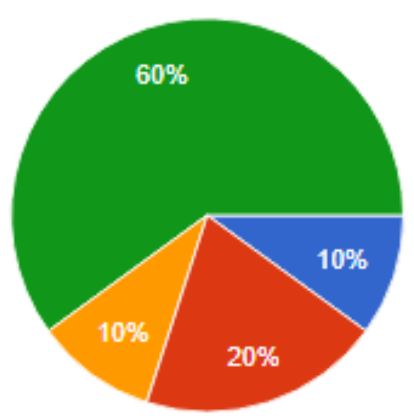

В основном в сыром виде

В жаренном

На пару или запечённую

В равной степени все виды обработки пищии

Большинство людей преклонного возраста в равной степени применяют все виды обработки пищи.

7. Часто ли вы добавляете соль в продукты?

20 ответов

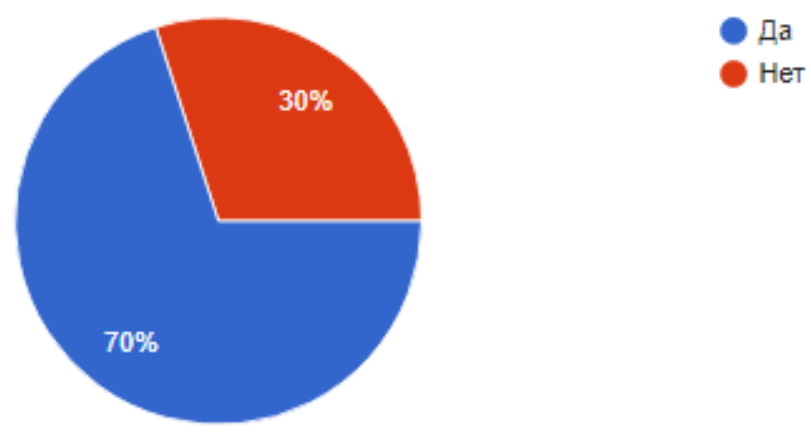

Большинство людей преклонного возраста добавляют соль в продукты.

8. Часто ли Вы употребляете консервированную пищу?

20 ответов

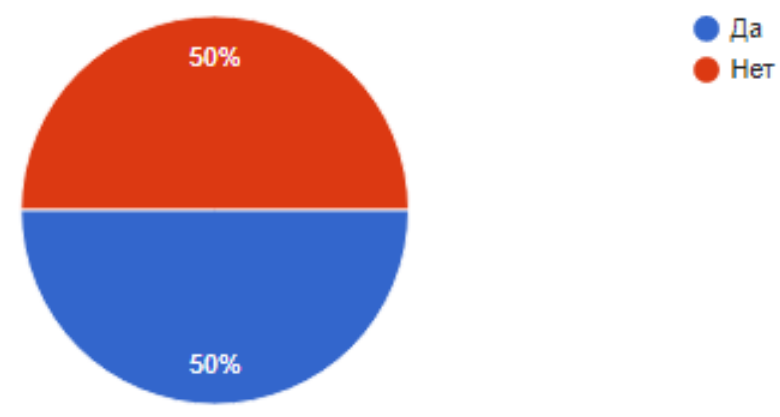

Таким образом, изучив и выполнив анализ можно сделать вывод, что по большей части, опрашиваемые люди пожилого возраста придерживаются тех правил, которые помогают им сохранять свое здоровье, касаемо рациона питания (исключение: употребление соли в немалых количествах и перекусы между основными приемами пищи).

Раздел «личная гигиена». 


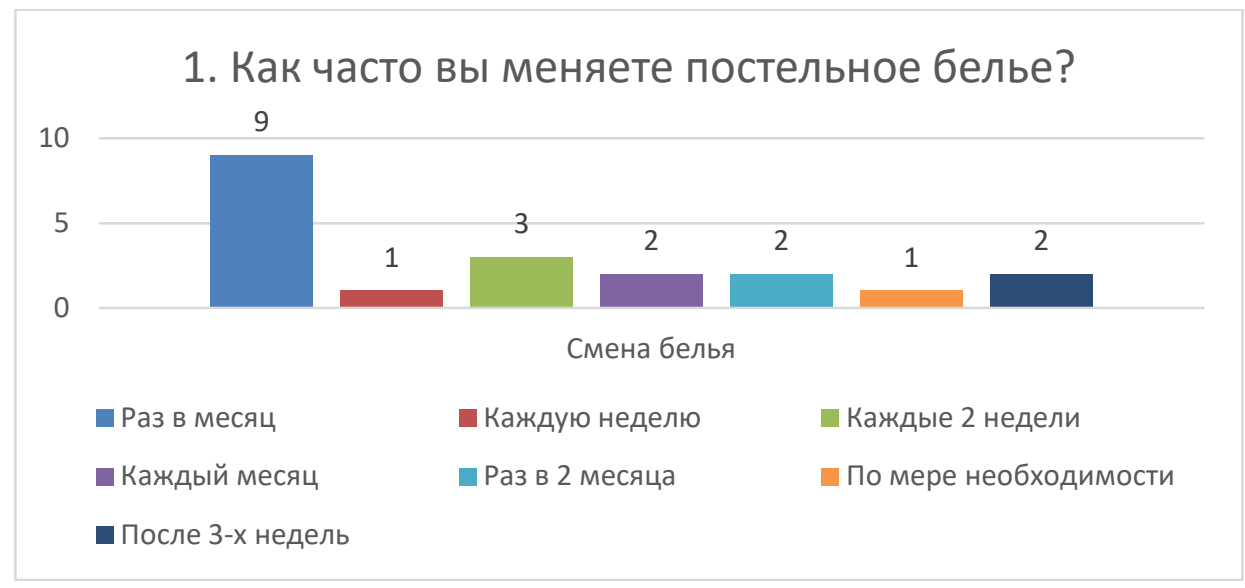

Большинство людей преклонного возраста меняют постельное белье раз в месяц.

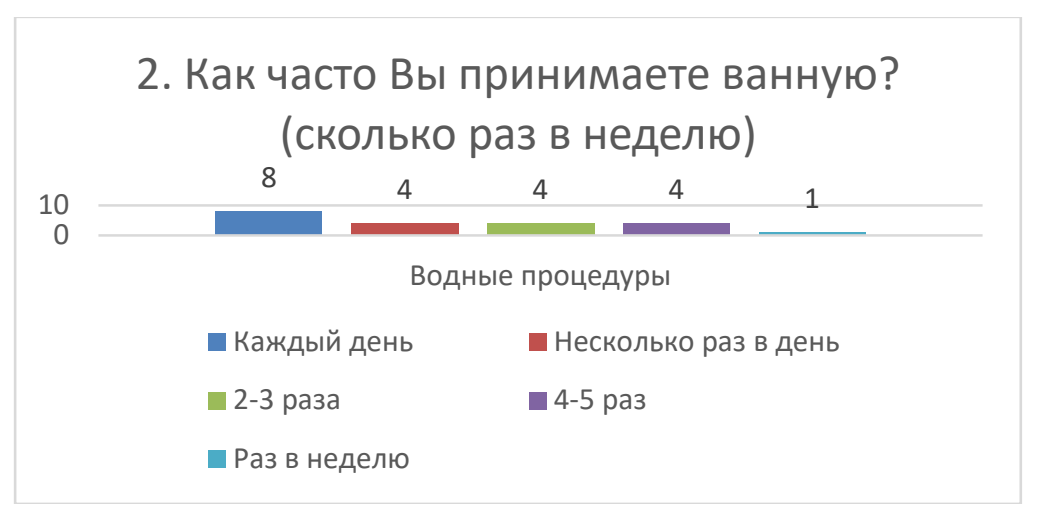

Большинство людей преклонного возраста принимают ванную каждый день.

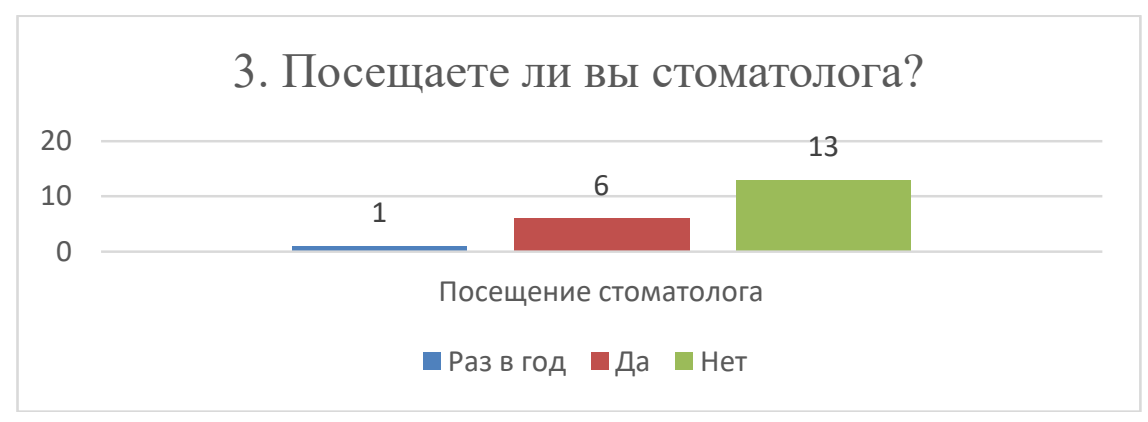

Большинство людей преклонного возраста не посещают стоматолога.

Так же можно сделать вывод, что интервьюеры в большинстве своем пренебрегают правилами личной гигиены, не посещая стоматолога и меняя пастельное белье раз в месяц.

Раздел «вредные привычки».

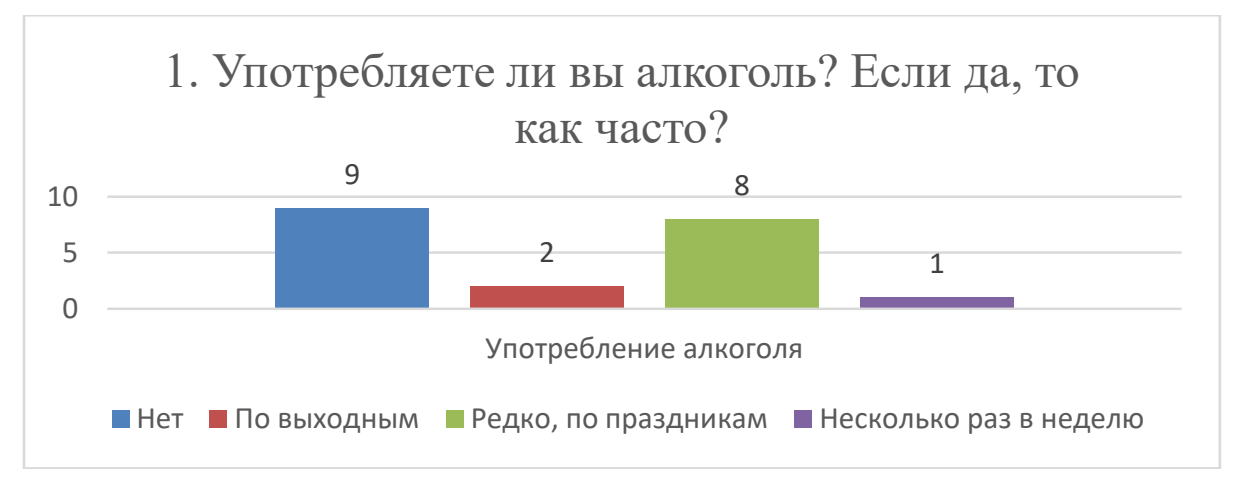


Больше половины людей преклонного возраста не употребляют алкоголь, а чуть меньше второй половины употребляют лишь по праздникам.

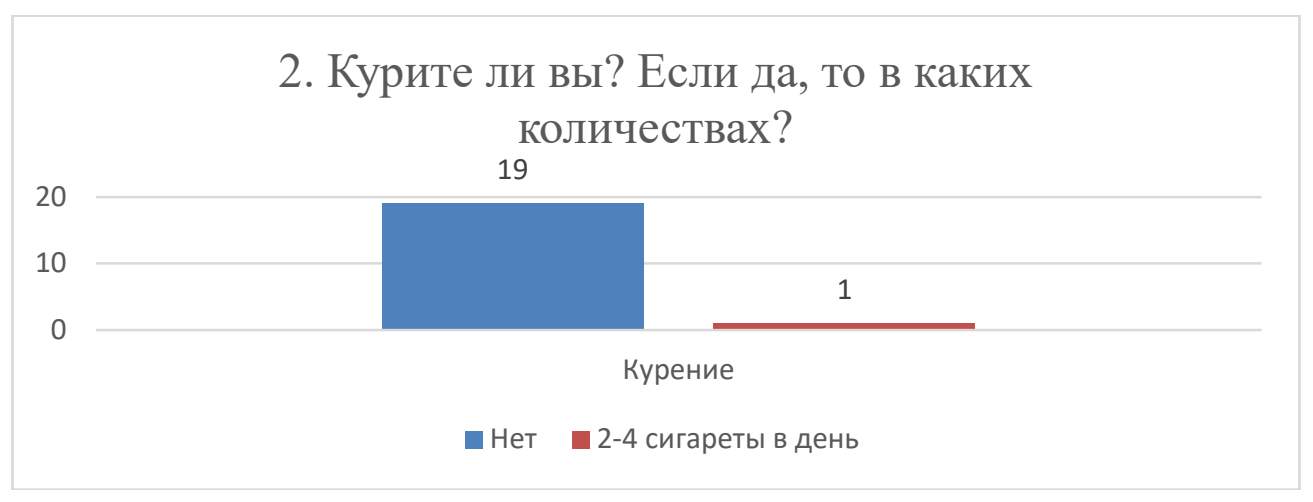

Почти все люди преклонного возраста не курят.

Отсюда можно сделать вывод, что среди опрашиваемых людей пожилого возраста есть лишь 1 человек-курильщик (5\% от общего), и 8 людей (40\% от общего), редко употребляющих алкоголь, хотя в идеале пенсионеры не должны употреблять алкоголь вовсе, как и курить.

Режим «двигательный режим».

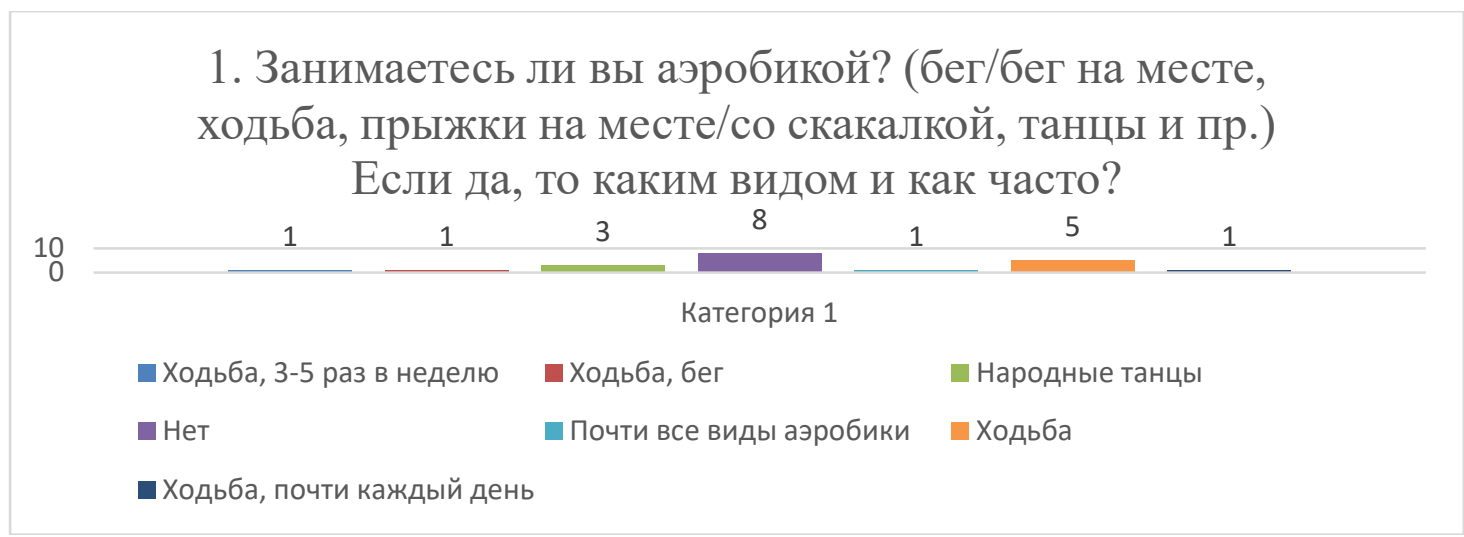

Половина из опрашиваемых людей преклонного возраста не занимаются аэробикой, остальные же предпочитают ходьбу.
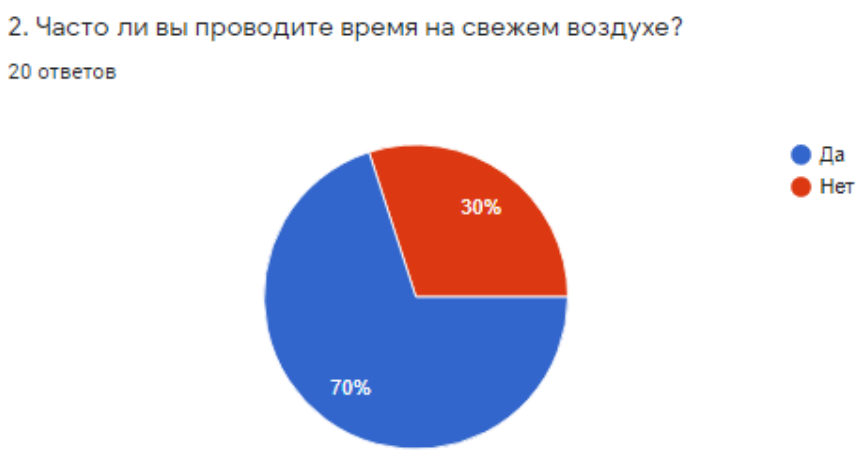

Большинство людей преклонного возраста часто проводят время на свежем воздухе.

Отсюда следует вывод, что люди преклонного возраста, как и полагается, часто проводят время на свежем воздухе, а также занимаются каким-либо видом активной деятельности (в большинстве своем - это хотьба).

Раздел «режим отдыха». 


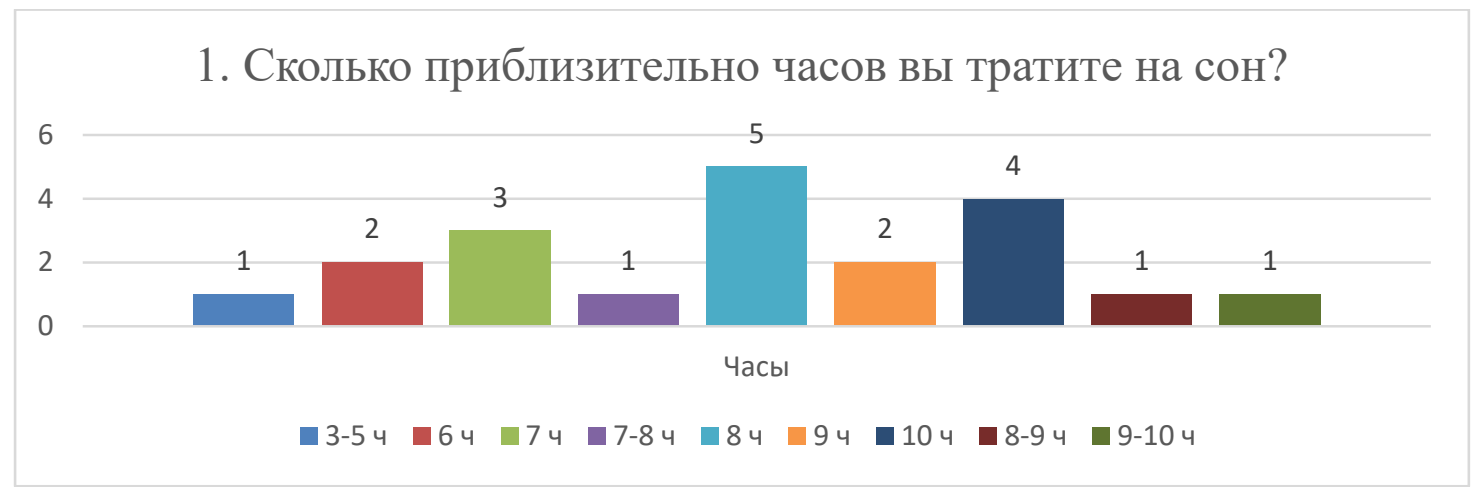

Большинство людей преклонного возраста тратят на сон около 8-10 часов.

2. Мучает ли вас бессонница?

20 ответов

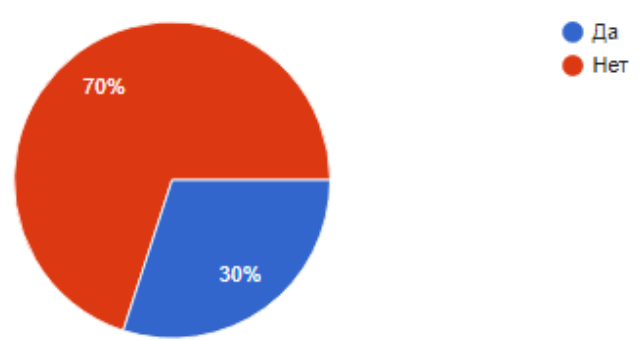

Большинство людей преклонного возраста не беспокоит бессонница.
3. Употребляете ли вы кофе перед сном?
20 ответов

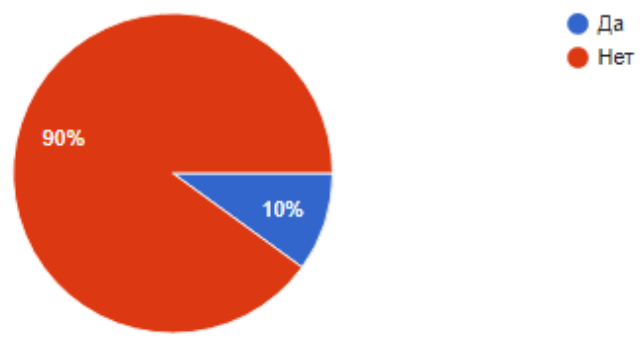

Почти все люди преклонного возраста не употребляют кофе перед сном.

4. За сколько часов до сна вы заканчиваете свой приём пищи? 20 ответов

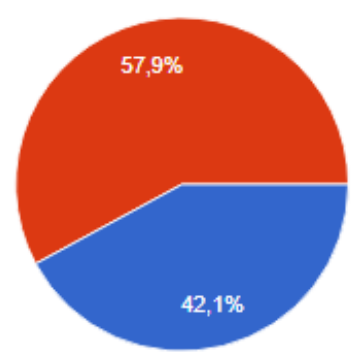

Менее, чем за 3 часа до сна

За 3 часа до сна или более

Больше половины людей преклонного возраста заканчивают свой прием пищи за 3 часа до сна и более. 

5. Спите ли вы днём?
20 ответов

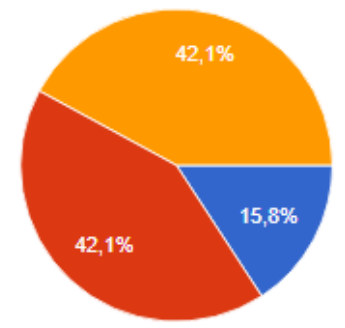

Большинство людей преклонного возраста предпочитают поспать днем.

Мы можем сделать вывод о том, что опрашиваемые люди пожилого возраста соблюдают режим отдыха (тратят на сон 8-10 часов, не употребляют крепкие напитки перед сном), однако не могут отказать себе в дневном сне, а также заканчивают свой последний прием пищи менее, чем за 3 часа до сна, что говорит о несоблюдении рекомендуемого режима отдыха.

Анализируя графики и диаграммы, можно сделать вывод, что многие люди преклонного возраста ведут не совсем здоровый образ жизни. Они часто перекусывают в течении дня, что можно негативно сказаться на балансе калорий и привести к ожирению. Весьма неплохими являются показатели личной гигиены у пенсионеров, они часто моются и меняют белье, в целом, одинаково, что препятствует возникновению вредителей. Кроме того, далеко не все посещают стоматолога или делают это довольно редко, что негативно сказывается на состоянии здоровья зубов и десен. Выяснилось, что большое количество опрошенных принимают алкоголь по праздникам, но для здорового образа жизни следует исключить его полностью, как и курение, но курящих оказалось немного. Можно сказать, что прогулки на свежем воздухе или другая активность присуща людям пожилого возраста, что укрепляет их иммунитет. В среднем, большинство пожилых людей тратят на сон около 8-10 часов, что соответствует норме. Из-за неупотребления кофе перед сном, люди, в большинстве своем не испытывают бессонницы, однако не брезгают вздремнуть днем, что не является нормой. Для хорошего сна необходимо заканчивать прием пищи не менее, чем за 3 часа до завершения дня, что потворствует здоровью пищеварительной системы и всего организма в целом.

$$
* * *
$$

1. Устав (Конституция) Всемирной организации здравоохранения // Электронный фонд правовой и нормативно-технической документации URL: http://docs.cntd.ru/document/901977493 (дата обращения: 25.12.2020 г.).

2. Федеральный закон «Об основах охраны здоровья граждан в Российской Федерации» от 21.11.2011 N 323 Ф3 (последняя редакция) // КонсультантПлюс надежная правовая поддержка URL: http://www.consultant.ru/document/cons_doc_LAW_121895/(дата обращения: 25.12.2020 г.).

3. Мы за здоровый образ жизни // URL: http://volno.baranovichi.edu.by/ru/main.aspx?guid=2021 (дата обращения: 25.12.2020 г.).

4. Составляющие здорового образа жизни // Управление федеральной службы по надзору в сфере защиты прав потребителей и благополучия человека по Ульяновской области URL: http://73.rospotrebnadzor.ru/content/156/7403/ (дата обращения: 25.12.2020 г.).

5. Основные принципы рационального питания пожилых людей // URL: https://www.7ya.ru/article/Osnovnyeprincipy-racionalnogo-pitaniya-pozhilyh-lyudej/ (дата обращения: 25.01.2020 г.).

6. Гигиена пожилых людей // URL: https://pansionat-osen.ru/poleznye-materialy/gigiena-pozhilyh-lyudej/ (дата обращения: 25.01.2020 г.).

7. Физическая
https://www.who.int/dietphysicalactivity/factsheet_olderadults/ru/ (дата обращения: 25.01 .2020 г.).

8. Вредные привычки у пожилых людей // URL: https://easycare.pro/blog/zhiznennoe-prostranstvo/vrednyeprivychki-u-pozhilykh-lyudey/ (дата обращения: 25.01.2020 г.).

9. Режим питания // URL: https://www.bsmu.by/page/3/5722/ (дата обращения: 25.12.2020 г.). 
10. Физическая гимнастика для людей, ведущих «сидячий» образ жизни // URL: https://vuzlit.ru/406009/fizicheskaya_gimnastika_lyudey_veduschih_sidyachiy_obraz_zhizni (дата обращения: 25.01.2020 г.).

11. Психологические особенности здорового образа жизни (ЗОЖ) // URL: https://urok.1sept.ru/articles/628392 (дата обращения: 25.01.2020 г.).

12. Факторы, определяющие здоровый образ жизни // URL: http://volno.baranovichi.edu.by/main.aspx?guid=1811 (дата обращения: 25.01.2020 г.).

13. Питание пожилых людей: основные принципы и правила // URL: https:/dom-prestarelyh.ru/blog/pitaniepozhilykh-lyudey/ (дата обращения: 25.04.2020 г.).

\section{Евтропкова Д.С. \\ Оценка функционального состояния студенток 1 курса по дисциплине «физическая культура и спорт» элективного направления «Фитнес» (опыт ПетрГУ)}

Петрозаводский государственньій университет

(Россия, Петрозаводск)

doi: 10.18411/trnio-11-2021-154

\section{Аннотация}

В 2016-2017 в Петрозаводском Государственном Университете (ПетрГУ) была внедрена система организации учебного процесса по физическому воспитанию по элективным направлениям с учетом требований ФГОС ВО 3+. Предварительное анкетирование студентов 1 курса позволило определиться с предпочтениями обучающихся. Одним из популярных направлений студентами была выбрана элективная дисциплина «Фитнес» [3, с. 140]. В процессе работы по улучшению качества преподавания дисциплины, с использованием нестандартных и новых видов фитнес технологий, использовать данные результаты исследования показателей функциональных проб дыхательной и сердечнососудистой систем для повышения функционального состояния организма студенток. Результатом исследования стал анализ влияния занятий на функциональное состояние организма студенток 1 курса вуза по дисциплине «физическая культура и спорт» элективной дисциплины «Фитнес». Проводится анализ проведенных функциональных проб, занимающихся, осознанно выбранном направлении электива «Фитнес» и посвящена данная статья.

Ключевые слова: ФГОС, учебный процесс, элективное направление, элективная дисциплина, фитнес, физическая культура, физическое воспитание, студенты, функциональные пробы, функциональное состояние, ПетрГУ.

\section{Abstract}

In 2016-2017 in Petrozavodsk State University (PSU) a new organisational system of the educational process of the physical education of the elective courses considering the Federative State Educational requirements "VO 3+" was introduced. Preliminary questionnaire helped to decide upon the preferences of the first-year students. "Fitness" as an elective discipline was chosen as the most popular one. During the process of working on the discipline teaching improvement with the use of new types of fitness technologies, for the development of the first-year students' functional state of the organisms, we are supposed to use the data from the research results: indexes of the functional tests of breathing and heart systems. The analysis of the impact of the physical activities on the organisms of the first-year students of the department of physical training with the elective course "fitness" are the results of the research. This article is devoted to the functional tests analysis of the students, who are aware of studying this course.

Keywords: FSES (federal state education standard), educational process, elective course, fitness, physical training, PSU (Petrozavodsk state university).

Фитнес, как спортивная специализация элективного выбора в ПетрГУ, на протяжении уже 4 лет является одним из наиболее популярных направлений среди девушек. Количество желающих заниматься на данном элективе ежегодно растет и на данный момент (2019/2020 уч год) составляет более 350 человек (17 учебных групп) [1, с. 5]. Занятия фитнесом 